\title{
DOÑA MENCÍA DE MENDOZA Y SU RESIDENCIA EN EL PALACIO DEL REAL EN VALENCIA ${ }^{1}$
}

Con la ayuda de varios documentos conservados en el Archivo del Palau, se dan a conocer diferentes enseres que Doña Mencía de Mendoza tenía en el Palacio del Real en Valencia, destacando camas de lujo como la de la Emperatriz Isabel de Portugal o la de María de Francia. Se dan a conocer algunos pintores activos en su corte como Juan de Bolaños.

Palabras clave: Siglo XVI; Inventarios; Guadamecíes; Tapices; Alfombras; Muebles; Pinturas; Iluminaciones; Juan de Bolaños.

Documents preserved in the Archivo del Palau reveal the furnishings that Mencía de Mendoza had in the Royal Palace at Valencia, particularly luxury beds such as those of the Empress Isabel of Portugal and Queen Mary of France. Painters active at her court, especially Juan de Bolaños, are also discussed.

Key words: $16^{\text {th }}$ century; Inventories; Embossed leathers; Tapestries; Rugs; Furniture; Paintings; Illuminations; Juan de Bolaños.

Hace algunos años publicamos sendos trabajos sobre Doña Mencía de Mendoza, Marquesa del Zenete, Condesa de Nassau y Duquesa de Calabria (1508-1554), donde dábamos a conocer el rico ajuar doméstico que acompañaba a esta ilustre dama durante sus sucesivas estancias en el castillo de Jadraque 2 . Ahora, gracias a la lectura de nuevos documentos, conservados en el

1 Este trabajo es parte de un proyecto de investigación (HAR2008-02349/ARTE) incluido dentro del "Programa Investigación Fundamental" del Plan Nacional de I+D+I (2008-2011), financiado por el Ministerio de Educación y Ciencia.

2 Hidalgo Ogáyar, J.: "Doña Mencía de Mendoza embajadora del arte español en Breda", en El Arte español fuera de España, XI Jornadas de Arte, Madrid, 2003, pp. 185-192.

Hidalgo Ogáyar, J.: "Doña Mencía de Mendoza y su residencia en el castillo de Jadraque", Archivo Español de Arte, n. ${ }^{\circ} 310,2005$, pp. 184-190.

Arch. esp. arte, LXXXIV, 333, ENERO-MARZO 2011, 59-90, ISSN: 0004-0428 
Archivo del Palau y que corresponden a los años en los que Doña Mencía estuvo residiendo en el palacio del Real en Valencia, podemos aportar más información sobre distintas adquisiciones que fue haciendo nuestra protagonista cuando, tras desposarse en 1541 con Don Fernando de Aragón, Duque de Calabria, pasó a habitar el citado palacio.

El palacio del Real era una construcción de origen árabe, se cree que fue utilizado como casa de recreo por el rey musulmán. Después de la conquista de Valencia por Jaime I, este lugar se convirtió en residencia de los reyes aragoneses y posteriormente, en el último cuarto del siglo XIII, se consolidó como palacio cristiano, realizándose importantes obras de remodelación que se continuaron durante las dos primeras décadas del siglo XIV y, sobre todo, durante el largo reinado de Pedro IV el Ceremonioso (1336-1387). En el siglo XV los aposentos del rey y de la reina, como en otros palacios de la corona de Aragón, se encontraban separados en las denominadas "casas", así las habitaciones de María de Castilla, esposa de Alfonso el Magnánimo, estaban situadas en la zona inmediata a la capilla, en torno al denominado patio pequeño, $\mathrm{y}$, según sus inventarios, estuvieron decoradas con abundantes colecciones de tapices, a las que se sumaron las pinturas de la capilla. Pero será en el siglo XVI con Don Fernando de Aragón, Duque de Calabria, cuando este palacio, sede de la corte virreinal, llegue a convertirse en uno de los lugares más suntuosos de la época ${ }^{3}$.

Como ya dijimos, al casarse Mencía de Mendoza con el Duque de Calabria en 1541, esta dama pasó a vivir al palacio del Real en Valencia, ya que dicho lugar era la residencia de su esposo desde que éste contrajera matrimonio con su anterior esposa Doña Germana de Foix ${ }^{4}$, y allí permaneció Mencía hasta su muerte, acaecida en 1554. Curiosamente su traslado a este palacio determinó que Don Fernando de Aragón decidiera construir dentro de sus muros una gran sala, para lo que se convocaron en 1542 a "mestres d'architectura"; ello supondrá la sustitución, por primera vez en Valencia, de las tradicionales ventanas góticas por unas nuevas con molduras clásicas ${ }^{5}$. Asimismo, la entonces Duquesa de Calabria se va a servir del arquitecto Gaspar Gregori, que será nombrado en 1559 "mestre Fuster de las obras del señor rey" para realizar otras intervenciones arquitectónicas en dicho palacio, como los cambios promovidos en sus dos cámaras, en la librería, en las habitaciones del sastre, el tesorero o el platero, en las caballerizas, en la cocina y, sobre todo más adelante, las obras realizadas para asentar el camerino del Duque de Calabria, que fue adquirido en la almoneda celebrada a la muerte de su esposo, en las que Gaspar Gregori será el encargado de adobar las ventanas de la habitación donde estaba el citado camerino, pintar la estancia y colocar una vidriera en la ventana con vistas al huerto, lugar este último por el que Mencía de Mendoza sentía una gran afición ${ }^{7}$.

En el Archivo del Palau se ha conservado un inventario del año 1548, donde se recogen diferentes enseres pertenecientes a Doña Mencía que había en esa fecha en el Palacio del Real ${ }^{8}$. Si comparamos este inventario con el que fue realizado trece años antes, concretamente el redactado

\footnotetext{
${ }^{3}$ Gómez-Ferrer, M. y Bérchez, J.: “El Real de Valencia en sus imágenes arquitectónicas”, Reales Sitios, n. ${ }^{\circ} 158$, 2003, pp. 33-47.

${ }^{4}$ Martí Ferrando, J.: "La Corte virreinal valenciana del Duque de Calabria", Reales Sitios, n. ${ }^{\circ}$ 158, 2003, pp. 16-32.

5 GÓMEZ-Ferrer, M. y BÉrChez, J.: op. cit., p. 35.

${ }^{6}$ Gómez-Ferrer, M.: Arquitectura y arquitectos en la Valencia del siglo XVI: el Hospital General y sus artifices, Valencia, 1996, pp. 210-243.

7 García PéRez, N.: Arte, poder y género en el Renacimiento español. El patronazgo artístico de Mencía de Mendoza, Murcia, 2006, pp. 327-328.

${ }^{8}$ Archivo del Palau, Marquesado del Zenete, leg. 122c.
} 
en el castillo de Jadraque en $1535^{9}$, con ocasión de la vuelta a Flandes de nuestra dama, podemos observar que todo su ajuar doméstico había crecido extraordinariamente.

\section{Guadamecíes, tapices y alfombras}

Así, de 32 piezas de guadamecíes que se mencionan en 1535 se pasó a 78 piezas en el inventario de 1548, descritas de la siguiente manera:

-18 piezas de guadamecíes de oro, plata y negro, decorados en el medio de cada uno de los cueros que los forman con una alcachofa con follaje alrededor a manera de brocado. Todos ellos estaban metidos en cuatro cajas de madera blanca.

-11 piezas de guadamecíes de plata con las apañaduras de oro.

-4 piezas de guadamecíes de oro, plata y verde, que eran las que se colgaban en la habitación que estaba entre la librería y el oratorio.

-27 piezas de guadamecíes de las armas. Estaban guardadas en tres arcas cuadradas negras.

-7 piezas de guadamecíes que estaban en la cámara de Doña Ana de Montalvo.

-11 piezas de guadamecíes que estaban en la biblioteca, de las que dos eran de oro, plata y verde, y las nueve restantes eran de cuero colorado con cenefas de oro y verde.

En cuanto a los tapices, también su número se amplió considerablemente, ya que, además de los comprados en Flandes durante los años en los que vivió allí Doña Mencía cuando contrajo matrimonio con Don Enrique de Nassau, dicha señora adquirió bastantes piezas en España, concretamente en las ferias castellanas de Medina del Campo y de Medina de Ríoseco e, incluso, se aprovechó de las almonedas que se originaban a causa de las herencias. De esta última manera, por ejemplo, adquirió la serie de los cinco sentidos, perteneciente al Cardenal de Lieja, Erardo de la Marca, cuyos testamentarios tuvieron que venderla para poder saldar ciertas deudas del finado ${ }^{10}$.

- En el citado inventario de 1548 aparecen mencionados 76 tapices distribuidos de la siguiente manera:

-8 paños de la tapicería de las Ilustres mujeres. Estaban en siete cofres negros.

-7 paños de la tapicería de la historia de Faetón.

-6 paños de la tapicería de los sentidos. Estaban guardados en dos arcas de madera blanca.

-5 paños de la tapicería de la historia de Jacob. Estaban en dos cofres negros.

-8 paños de la tapicería de las muertes ${ }^{11}$. Estaban envueltos en gruesas arpilleras.

- 19 paños de la tapicería de la verdura.

- La tapicería de la caída comprendía:

-6 paños de la historia de David y Salomón.

-5 paños de la historia de José, de los que 3 eran paños de antepuerta.

-6 entresuelos de tapicería de la historia de Josué.

Además había:

-3 paños pequeños de tapicería de los que estaban en el castillo de Ayora.

-1 paño pequeño de tapicería con la representación de Dios creando la tierra.

\footnotetext{
9 Archivo del Palau, Marquesado del Zenete, leg. 122-15.

10 García PÉrez, N.: op. cit., p. 259.

11 Esta tapicería iba a servir para decorar los muros de la capilla funeraria de Mencía de Mendoza en el Monasterio de Predicadores de Valencia. El pintor Van Orley fue el encargado de realizar los cartones: García Pérez, N.: op. cit., p. 258.
} 
-2 antepuertas, una con la Virgen bajo un dosel en el centro y otra con San José.

Como podemos observar, no todos los tapices se encontraban expuestos, sino que algunos, según se dice, estaban guardados en arcas, cajas o cofres, así ocurría, por ejemplo, con la serie de los sentidos que, como apuntamos más arriba, fue adquirida por Doña Mencía en la almoneda del Cardenal de Lieja, Erardo de la Marca, tras su fallecimiento en 1538.

Curiosamente, de los 76 tapices citados ninguno coincide exactamente con los enumerados en el inventario de 1535, donde sólo se aludía a una serie denominada de la Pesca (diez paños), a otra referente a Perseo (siete paños), a una relativa a la historia de Isaac (adquirida en España) y, por último, a la de la gruta (diez paños, tres con verduras).

Unos años después, en un inventario mandado realizar en $1560^{12}$ por Don Luis de Requesens, Comendador Mayor de Castilla, tras haber ganado el pleito que se había originado por la herencia de Doña Mencía ${ }^{13}$, se mencionan nuevos tapices que debieron ser adquiridos con posterioridad a 1548 y que, tras el fallecimiento de dicha señora, se habían depositado, junto con los citados anteriormente, en el Monasterio de Predicadores y en la sacristía de la Seo de Valencia. Estos nuevos tapices eran:

-5 paños de la tapicería de la historia de la Reina Ester.

-8 paños de la tapicería de la historia de Cristina.

Respecto a las alfombras, su número también aumentó de forma considerable, ya que en el inventario de 1548 se citan hasta catorce alfombras, entre las que había cinco grandes, y veintisiete tapetes turquescos, descritos todos ellos de esta manera:

-2 alfombras grandes de seda turquesca colorada y blanca.

-1 alfombra grande negra turquesca de labores blancas.

-1 alfombra grande de ruedas de muchos colores (amarillo, blanco, azul, verde, colorado).

-1 alfombra grande verde y colorada de ruedas.

-6 alfombras de las ordinarias.

-3 alfombras de Alcaraz de color verde y colorado, perfiladas de amarillo.

-7 tapetes turquescos con una flor en el centro y orla alrededor de diferentes colores.

-10 tapetes turquescos, unos con tres ruedas de colores y orlas de colores y otros con flores de colores y orlas de colores

-5 tapetes turquescos viejos, dos de ellos estaban debajo del armario de la librería.

-5 tapetes turquescos negros, colorados y blancos que estaban rotos por el medio y estaban en el suelo de la librería.

\section{Muebles}

Por lo que respecta al mobiliario, ya sabemos que en esa época no era muy numeroso y se repartía, especialmente, en torno al dormitorio, la recámara según los inventarios, donde la cama de

12 Archivo del Palau, Marquesado del Zenete, leg. 122-18.

13 Este pleito se había iniciado seis años antes, en 1554, entre el Comendador Mayor de Castilla Don Luis de Requesens, primogénito de Don Juan de Zúñiga, que había sido escogido por nuestra dama en su testamento, redactado en Burgos el 3 de julio de 1535, como heredero universal de todos sus bienes libres y partibles, y los Condes de Saldaña, Don Diego Hurtado de Mendoza y su esposa María de Mendoza, que, no conformes con haber heredado el Marquesado del Zenete, pretendían, también, apoderarse de los bienes libres de su cuñada y hermana respectivamente; y además el Marqués de Mondéjar, quien habiendo prometido una importante dote a su hija Doña Francisca cuando ésta se casó con Don Baltasar Ladrón, dote de la que Doña Mencía de Mendoza se había ofrecido como fiadora, dejó de abonar a su hija y yerno 18.000 ducados de la mencionada dote, intentando conseguir dicha cantidad de la herencia de nuestra protagonista, por lo que también puso un pleito al Comendador. 
colgaduras con dosel, cortinajes y colcha de brocado destacaba por su gran riqueza y se convertía, con frecuencia, en el mueble más importante; baste recordar las diversas camas enumeradas en anteriores inventarios de Jadraque ${ }^{14}$, Simancas ${ }^{15}$ y Breda $^{16}$. Es por ello que Mencía de Mendoza, deseando poseer las camas más lujosas, aprovechara la almoneda que se hizo tras el fallecimiento de la Emperatriz Isabel de Portugal $(† 1539)$ para adquirir, por mediación de Doña Estefanía de Requesens, una cama de nácar que costó 201 ducados ${ }^{17}$.

No hay duda en afirmar que esta cama es la misma que la descrita por la profesora Redondo Cantera en su trabajo sobre las pertenencias de la esposa de Carlos V, Isabel de Portugal ${ }^{18}$. De ella dice que es una cama de gran tamaño, con seis pilares y pies cubiertos de nácar de colores y con algunas piedras engastadas en dichos pilares, procedente del Lejano Oriente, quizás obra coreana, y que, debido a su rareza, su tasación fue muy dificultosa, ya que no había nadie que pudiera hacer una valoración ajustada. Sin embargo, gracias al documento conservado en el Archivo del Palau, sabemos que fue tasada en 201 ducados y que fue adquirida para Doña Mencía por Doña Estefanía de Requesens.

Asimismo, en el inventario de 1548 aparece descrita una riquísima cama de oro, cubierta con un dosel formado con veinte cuadrados labrados en oro y sedas de colores, de la que se dice que era de la reina ${ }^{19}$, y que pensamos que o bien fuera un regalo de la Reina María de Francia (hermana del Rey de Inglaterra Enrique VIII y 3. ${ }^{a}$ esposa del Rey de Francia Luis XII) a Doña Mencía, o, lo más probable, que la Marquesa del Zenete la adquiriera tras el fallecimiento de dicha Reina en 1533.

Además de las camas, gracias a este mismo inventario de 1548, conocemos la presencia en el palacio del Real de los siguientes muebles:

-Una mesita de taracea con las bisagras de plata y con su banquito, curiosamente se dice que estaba dentro de un arca blanca encorada.

- Una mesa de plata con las armas de Calabria y de Mendoza, podría ser la realizada por el platero de Valencia, Bernat Juan Cetina ${ }^{20}$.

- Una mesa de nogal hecha de diversas piezas, con las bisagras doradas y sobre ellas estaban las armas de los Mendoza.

-Dos mesas de nogal labradas de taracea.

- Dos mesas llevadas desde Alemania

- Una mesa de nogal de tres piezas, con bisagras y dos pies en forma de tijera.

- Una mesita de madera blanca donde se ponían los candeleros.

- Una mesita de madera blanca que utilizaba Doña Mencía para escribir.

- Una mesa de nogal con tiras de otra madera más negra que servía para decir misa.

- Un armario de madera, dorado, con cajones, dos anillas y un escudo de plata.

-Un armario de nogal con puertas y cajones, forrado de terciopelo verde, con cerradura, llave y escudo de armas.

- Un armario blanco de madera de álamo, con cajones, puertas y cerradura.

- Cinco sillas con los asientos y respaldos de brocado.

\footnotetext{
14 Archivo del Palau, Marquesado del Zenete, leg. 122-20, 122-15.

15 Archivo del Palau, Marquesado del Zenete, leg. 122-c.

16 Archivo del Palau, Marquesado del Zenete, leg. 122-5.

17 Archivo del Palau, Marquesado del Zenete, leg. 137-5.

18 Redondo Cantera, M. J.: "Las improntas lusa y oriental en la recámara de la emperatriz Isabel de Portugal", en Las Relaciones Discretas entre las Monarquias Hispana y Portuguesa: Las Casas de las Reinas (siglos XV-XIX), vol. III, Madrid, 2008, pp. 1537-1561.

19 Archivo del Palau, Marquesado del Zenete, leg. 122c, folios 11v y 12r.

20 Archivo del Palau, Marquesado del Zenete, leg. 135.
} 
-Diecisiete sillas con los asientos y respaldos de sedas de colores.

- Doce sillas con los asientos de cuero.

- Varios doseles.

Más adelante, por un documento fechado entre 1552 y 1553, sabemos que Doña Mencía también llegó a poseer un oratorio de madera, en parte dorado y pintado de diferentes colores, y que encima de la puerta mostraba las armas de las infantas y en las esquinas se situaban las imágenes de las nueve musas con sus nombres y un letrero encima. Por dentro, en el cielo, estaba representado el templo de Jerusalén, unas frutas pintadas y unos letreros con la frase "deo gracias". Tenía una ventana con su reja de madera y dos cajones dorados y en ellos estaban pintados un pájaro dentro de una jaula y un perro. En medio del oratorio había un altar pequeño con un frontal de raso carmesí y raso verde, guarnecido de franja de oro y grana y seda verde. El altar se cubría con una toalla morisca vieja de seda, listada en blanco y negro ${ }^{21}$.

Por la fecha en la que se describe este oratorio y del que se dice que había pertenecido a las infantas (posiblemente Doña María y Doña Juana, hermanas de Felipe II), nos hace suponer que dicho objeto se habría quedado en la corte española tras la marcha de ambas princesas, al desposarse una con el emperador de Alemania en 1548 y otra con el rey de Portugal en 1552, pasando de alguna manera, que desconocemos, a ser propiedad de Doña Mencía.

\section{Pinturas}

En cuanto a las pinturas se puede observar que entre 1535, fecha en la que se hizo el inventario en el castillo de Jadraque antes de regresar a Flandes, y 1548, cuando se realizó el inventario del palacio del Real en Valencia, la colección de pinturas de Mencía de Mendoza había aumentado de forma extraordinaria. Así de las 66 obras que se mencionan en el inventario de 1535 se pasaron a 220 en su residencia de Valencia, constatándose que todas las pinturas anteriores las había mantenido Doña Mencía en su poder a excepción de: una Adoración de los Reyes, dos de sus cinco retratos y uno de los tres retratos de su esposo el Conde de Nassau.

De estas 220 pinturas inventariadas, 137 estaban realizadas sobre tabla y 83 sobre lienzo. De algunas de ellas se dice, además, donde estaban colocadas, así 5 estaban en el retablo del oratorio, 26 en el oratorio, 114 en la librería (74 sobre tabla y 40 sobre lienzo) y 11 en una habitación entre la librería y el oratorio; de otras 64 (33 sobre tabla y 31 sobre lienzo) se apunta que no están expuestas en ninguna habitación. La temática más abundante era la religiosa y el retrato, a los que acompañaban, en menor número, otros cuadros de temas literarios y mitológicos, además de algunas vistas de ciudades, mapamundis y batallas. Los retratos en total sumaban 65 $\mathrm{y}$, fundamentalmente, se exponían en la librería, formando lo que se ha considerado la primera galería de retratos del Renacimiento español, anticipándose en el tiempo a la del palacio del Pardo de $1563^{22}$ y tomando como referencia las galerías de retratos de la nobleza flamenca que Doña Mencía debió conocer durante su estancia en los Países Bajos, entre las que destacaban la de Margarita de Austria en el palacio de Malinas y la de María de Hungría en el palacio de Turnhout.

A lo largo de todo el inventario de 1548 sólo aparece mencionado en cuatro ocasiones el nombre del artista, en tres de ellas se alude a "Jeronimo Bosque" y en una cuarta a "Joanin de Mavux" 23 (tal como observó Fernando Benito Doménech, esta pintura de "Joanin de Mavux"

\footnotetext{
21 Archivo del Palau, Marquesado del Zenete, leg. 122-8.

22 GARCía PÉReZ, N.: op. cit., p. 330.

23 "yten otra pintura de jeronimo bosque de un viejo y una vieja con una guarnision de madera a la redonda el viejo con una sesta de huevos en la mano/ es de lienço"
} 
coincide con la representación de la Virgen y el Niño de Jean Gossaert Mabuse que se conserva, actualmente, en el Museo Cleveland) ${ }^{24}$.

Por lo que respecta a encargos hechos a pintores españoles, hasta el momento, sólo se conocían dos, uno, el encargo que la Marquesa del Zenete había realizado en 1546 a Bonavida, Procurador Patrimonial de Valencia en Valladolid, ordenando que Alonso Berruguete copiara la obra de Gossaert que mostraba el retrato de Don Juan de Zúñiga, Comendador Mayor de Castilla, y que éste tenía en su casa de León ${ }^{25}$; y dos, la contratación de Juan de Juanes ${ }^{26}$ para la realización de los retratos de los Duques de Calabria, tal como relata Marcos Antonio de Orellana en su libro Valencia antigua y moderna, donde escribe que "vio los retratos del Duque de Calabria y su mujer que hizo Joan de Joanes en la celda prioral del Monasterio de San Miguel de los Reyes ${ }^{27}$.

A ello, ahora se puede añadir, gracias a un documento que hemos encontrado en el Archivo del Palau, que el pintor Juan de Bolaños trabajó para Doña Mencía de Mendoza, por lo que recibió 19 ducados en 1540 , nueve ducados fueron por el oro y diez por sus trabajos y manos ${ }^{28}$. Desconocemos la obra en cuestión, pero, según especifica el cobro del dinero, se puede decir que Bolaños era, además de pintor, dorador.

Los Bolaños eran una familia de pintores que trabajaron en Valencia durante el siglo XVI. Así, Juan de Bolaños se encuentra citado en la Tacha Real de 1528 entre los pintores pertenecientes a la Parroquia de San Martín de dicha ciudad, mientras que el nombre de Luis de Bolaños aparece en la Tacha Real de 1547 de la Parroquia de San Juan ${ }^{29}$. También sabemos que un pintor llamado Lucas Bolaños estaba activo en la segunda mitad del siglo XVI en Valencia, realizando en 1585 pinturas de tema religioso sobre guadamecíes para la Generalidad de Valencia ${ }^{30}$. Además, un posible miembro de esta familia, llamado Juan de Bolaños, trabajó como pintor en

\footnotetext{
"yten otra pintura de jeronimo bosque de la torre de babilonia tiene de alto/ es de lienço"

"yten otra pintura de jeronimo bosque de san joan evangelista tiene un caliz en la mano tiene de alto una vara y tres palmos y de ancho una vara y un palmo/ es de lienço"

"yten una ymagen de nuestra señora con su yjo enbrassos vestida de azul con un letrero en baxo de la orla tiene una guarnision de madera a la redonda pintada a manera de jaspe es la mano de joanin de mavux tiene tres palmos de alto y dos palmos de ancho".

24 Benito Doménech, F.: "Introducción", La clave flamenca en los primitivos valencianos, Valencia, 2001, pp. 23-62

25 Archivo del Palau, Marquesado del Zenete, leg. 129 y 132; citado por Lasso DE LA Vega y López de Tejada, M. (Marqués del Saltillo): "El retrato del Comendador Mayor Don Juan de Zúñiga", Arte Español, t. XIII, 1941, pp. 4-8.

${ }^{26}$ Recientemente Fernando BenITo DomÉNECH en su estudio sobre Juan de Juanes ("Aspectos inéditos en la pintura de Joanes", Joan de Joanes. Un maestro del Renacimiento, Madrid, 2000, pp. 28-33, e "Introducción", La clave flamenca..., pp. 23-62) ha constatado la influencia que debió ejercer en el entorno valenciano, incluido Juanes, la colección de pintura flamenca de la Marquesa del Zenete. Esta afirmación ha motivado que Noelia García, en su afán de encontrar alguna obra de dicho pintor que hubiera pertenecido a Mencía de Mendoza, haya trascrito incorrectamente en su libro publicado sobre esta dama (Arte, poder y género..., p. 239) la descripción de uno de los cuadros que se enumeran en el inventario de 1548, para después decir que esta obra coincide con el Juicio de Paris, conservado en el Civici Musei e Gallerie di Storia ed Arte de Udine, que fue pintado por Juan de Juanes. La transcripción incorrecta es: "otra pintura de las tres diosas con un campesino colorado pintado naranja verde sobre la cabeça muchas perlas tiene de alto dos palmos y medio y de ancho vara y media". La transcripción correcta es: "yten otra pintura de las tres diosas con un corpesico colorado pintado en campo verde y sobre la cabesa muchas perlas tiene de alto dos palmos y medio $y$ de ancho media vara".

27 Orellana, M. A. de: Valencia antigua y moderna, Valencia, 1923.

28 Archivo del Palau, Marquesado del Zenete, leg. 142-9.

${ }^{29}$ Falomir, M.: La pintura y los pintores en la Valencia del Renacimiento (1472-1620), Valencia, 1994.

30 Albana Fernández, S.: Guía abreviada de artistas valencianos, Valencia, 1970.
} 
Andújar (Jaén) en el último tercio del siglo XVI; por su testamento, redactado en mayo de 1590, sabemos que era natural de Valencia, era hijo de un tal Juan de Bolaños y ejercía, también, el oficio de dorador ${ }^{31}$.

Como ya apuntamos, tras la muerte de Doña Mencía en 1554, se inició un pleito por su herencia entre el Comendador Mayor de Castilla, Don Luis de Requesens, cuyo padre, Don Juan de Zúñiga, había sido escogido por nuestra dama en su testamento, redactado en Burgos el 3 de julio de 1535, como heredero universal de todos sus bienes libres y partibles, y los Condes de Saldaña, por un lado, y el Marqués de Mondéjar, por otro, que se consideraban, también, sus herederos. Por ello, se obligó a que parte de los bienes de Doña Mencía de Mendoza fueran requisados por la Audiencia Real de Valencia y depositados, provisionalmente, en distintos lugares de la ciudad hasta que se resolviera el litigio. El pleito duró seis años y en 1560 el Comendador Mayor, estando en Guadalajara con motivo del enlace de Felipe II e Isabel de Valois, conoció que la Chancillería de Valladolid había fallado a su favor. De ahí que en ese mismo año mandara hacer diferentes inventarios de las pertenencias de nuestra dama que habían sido guardadas en distintos sitios de la ciudad de Valencia, como el Monasterio de la Merced, el Monasterio de la Misericordia, la sacristía de la Seo, el Monasterio de Predicadores y el Monasterio de San Miguel, para su posterior venta en almoneda.

Uno de estos inventarios muestra los precios en los que fueron vendidas algunas de las pinturas $^{32}$, dato, por cierto, que nos ha permitido constatar el poco valor que tenía todavía la pintura dentro de la sociedad española del último tercio del siglo XVI y, aún más, si lo comparamos con las tasaciones que se hicieron de las joyas y otros objetos realizados con materiales nobles.

Así, ninguna de las pinturas mencionadas superó las 8 libras y de ellas las más estimadas fueron siempre las de temática religiosa. Por ejemplo, las cuatro tablas que representaban diversos momentos de la Pasión de Cristo ("La oración en el huerto", "La coronación de espinas", "Cristo antes de la Crucifixión" y "Cristo con la cruz a cuestas"), que, según algunos investigadores, fueron pintadas por Van Orley entre 1530 y $1533^{33}$ y que siempre acompañaron a Doña Mencía, fueron de las mejor vendidas, pues una lo hizo por 8 libras y 1 sueldo; otra por 7 libras y 5 sueldos; la tercera por 7 libras; y la cuarta por 6 libras, pero, eso sí, sin mencionar para nada el nombre del pintor, que, con toda seguridad, se desconocía en ese momento.

El resto de las pinturas religiosas, en número de treinta, oscilaron entre las 3 libras y 1 libra, aunque algunas no llegaron ni siquiera a la libra. La excepción estaría en un retablo con dos puertas que contenía a María con su Hijo, vendido en 6 libras, y una tabla con la degollación de San Juan Bautista, vendido en 7 libras. Este último precio lo alcanzaron también dos esculturas de la Virgen, una de mármol y otra de alabastro.

Respecto a los retratos (se enumeran 31), su valoración fue aún menor, pues ninguno alcanzó las 2 libras, incluso diecinueve de ellos se vendieron todos juntos en un lote por 15 libras. Ni siquiera el que apareciese citado en algún momento el nombre del Bosco supuso un incremento del precio, pues un retrato que se dice hecho por este pintor costó solo 1 libra y 4 sueldos. Sin embargo llama la atención que una pintura de una mujer desnuda al lado de una fuente, obra que también fue adquirida por Doña Mencía durante su primera estancia en los Países Bajos y que siempre la acompañó en todos sus desplazamientos, fuera vendida por 5 libras y 7 sueldos, es decir, un precio semejante al de las pinturas de temática religiosa.

31 Domínguez Cubero, J.: "Pintores giennenses del siglo XVI. Los Bolaños en la transición protobarroca", Boletín del Instituto de Estudios Giennenses, n. ${ }^{\circ}$ 181, 2002, pp. 145-185.

${ }^{32}$ Archivo del Palau, Marquesado del Zenete, leg. 122-18.

33 García PÉReZ, N.: op. cit., pp. 228-230. 


\section{Iluminaciones}

Además de los numerosos manuscritos iluminados, muchos de los cuales eran Libros de Horas $^{34}$, Doña Mencía de Mendoza atesoró otras iluminaciones, tales como una serie de pequeñas pinturas iluminadas sobre pergamino o pape ${ }^{35}$, entre las que había cuatro retratos suyos (en uno se mostraba vestida con una saya de terciopelo negro recamada en oro, con mangas de raso carmesí bordadas también en oro, botones de diamantes y cabos de perlas, sobre la cabeza una gorra con su joyel y pluma y en las manos un libro de horas; en otro iba vestida de la misma manera, pero llevaba una pequeña jarra en las manos; en un tercero, de formato redondo como los anteriores, se vestía con una saya de raso carmesí, recamada toda de plata y unas manguillas de terciopelo azul con una chapería de cabos de oro y botones en las mangas y cabos de oro en la saya, un gorguerín de perlas de dos vueltas, se cubría la cabeza con una gorra que tenía un medallón, un joyel y una pluma, y en las manos llevaba un libro de horas; por último, en la cuarta pintura, de formato rectangular, Doña Mencía llevaba puesta una saya de plata frisada, forradas las mangas con tela de oro morada con cabos de perlas y unas manguillas de raso carmesí recamadas con botones de diamantes, un gorguerín de piedras y perlas, un collar de rubíes y esmeraldas, en la cabeza tenía, además de una gorra aderezada con un joyel y una pluma, una perla grande redonda y otra alargada colgando, en las manos sostenía una jarrita de agua). De su primer marido, Don Enrique de Nassau, había dos retratos (los dos eran de formato redondo y en ambos el Conde vestía una saya de raso negro, forrada con pieles de martas y de su cuello colgaba el toisón). También había un retrato de la reina de Francia y hermana de Carlos V, Doña Leonor (iba vestida con una saya de brocado con botones de balas y manguillas de carmesí oscuro, recamadas de plata, con botones de oro y gorguerín de diamantes y perlas, en la cabeza llevaba una cofia de perlas y un joyel, en la mano sostenía una carta de Mencía de Mendoza). A tenor de sus descripciones, se puede decir que estos retratos iluminados eran bastante parecidos a los retratos pintados que, de estos mismos personajes, se conservan hoy día en distintos museos (retratos de Don Enrique de Nassau en Anhaltische Gemäldegalerie de Dessau y en el Museo de arte de Cataluña, retrato de Doña Mencía en el Museo Condé de Chantilly, retrato de Leonor de Austria en el Kunsthistorisches Museum de Viena).

Tras el fallecimiento de Doña Mencía de Mendoza, dichas iluminaciones fueron llevadas al convento de San Miguel en Valencia a la espera de que se resolviera el litigio por la herencia de esta señora.

Hoy día, que sepamos, sólo se conservan sobre pergamino los retratos de Don Enrique y Doña Mencía de los Museos estatales de Berlín. Son dos pequeñas piezas, de forma rectangular, que muestra cada una la efigie de uno de ellos. Se venían atribuyendo a Gossaert, aunque últimamente se ha sugerido que podían ser obra del famoso miniaturista Simón Bening ${ }^{36}$. Sin embargo, ninguno de los dos retratos coincide exactamente con las descripciones que se hacen de los retratos iluminados en el anterior documento del Archivo del Palau.

Finalmente, en el inventario realizado en mayo de $1563^{37}$, figuran, entre los numerosos objetos que habían pertenecido a Doña Mencía, unos libros de oro pequeños, cuyas hojas eran de pergamino con alguna iluminación y que, dado su tamaño, pensamos que podrían llevarse col-

\footnotetext{
34 Sobre los Libros de Horas ver: Hidalgo Ogáyar, J.: "Libros de Horas de Doña Mencía", Archivo Español de Arte, n. ${ }^{\circ}$ 278, 1997, pp. 177-183, e Hidalgo OgÁyar, J.: Libro de Horas de Doña Mencía de Mendoza, estudio crítico, Madrid, 2002.

35 Archivo del Palau, Marquesado del Zenete, leg. 122-3.

${ }^{36}$ Kren, T.: "Simon Bening", en Illuminating the Renaissance. The Triumph of Flemish Manuscript Painting in Europe, Los Ángeles, Paul Getty Museum, 2003, pp. 465-466.

37 Archivo del Palau, Marquesado del Zenete, leg. 122-18.
} 
gados, por ejemplo, de la cintura y sus oraciones leerse en cualquier momento, ya que con toda seguridad serían libros de devoción privada. El carácter lujoso de este tipo de libros hacía que se inventariaran con las joyas personales y así aparecen dentro de un lote de joyas que fueron entregadas a Blas de la Cava para que las vendiese en pública subasta y con el dinero resultante pagase la dote de Doña Catalina de Mendoza, esposa de Don Juan de Quintana. Su tasación osciló entre las diez libras y las siete libras.

JuAna Hidalgo OgÁyar

Universidad de Alcalá 